\title{
Detectable Depth of Copper, Steel, and Aluminum Alloy Plates with Pulse-Echo Laser Ultrasonic Propagation Imaging System
}

\author{
Dong-Il Kim ${ }^{1} \mathbb{D}$, Ku-Rak Jung ${ }^{2}$, Yoon-Soo Jung ${ }^{3} \mathbb{D}$ and Jae-Yeol Kim ${ }^{4, *(D)}$ \\ 1 Department of Physics, Korea University, Seoul 02841, Korea; kdong1research@gmail.com \\ 2 AI Energy Research Center, Korea Photonics Technology Institute, Gwangju 61007, Korea; krjung@kopti.re.kr \\ 3 R\&D Center, WINIADIMCHAE Co., Ltd., Seongnam-si 13217, Gyeonggi-do, Korea; \\ yoonsoo_jung@winiadimchae.com \\ 4 Department of Mechanical Engineering, Chosun University, Gwangju 61452, Korea \\ * Correspondence: jykim@chosun.ac.kr; Tel.: +82-62-230-7745; Fax: +82-50-7081-7274
}

check for

updates

Citation: Kim, D.-I.; Jung, K.-R.; Jung, Y.-S.; Kim, J.-Y. Detectable

Depth of Copper, Steel, and

Aluminum Alloy Plates with

Pulse-Echo Laser Ultrasonic

Propagation Imaging System. Metals

2021, 11, 1607. https://doi.org/

$10.3390 /$ met11101607

Academic Editors: Thomas Niendorf and Cătălin-Daniel Constantinescu

Received: 23 August 2021

Accepted: 29 September 2021

Published: 9 October 2021

Publisher's Note: MDPI stays neutral with regard to jurisdictional claims in published maps and institutional affiliations.

Copyright: (c) 2021 by the authors. Licensee MDPI, Basel, Switzerland. This article is an open access article distributed under the terms and conditions of the Creative Commons Attribution (CC BY) license (https:/ / creativecommons.org/licenses/by/ $4.0 /)$.

\begin{abstract}
Pulse-echo laser ultrasonic propagation imaging is a nondestructive testing technique developed for composite materials and aluminum alloys used in aerospace. Although this method has been in usage for a considerable time, information of the detectable depth and the relationship between ultrasonic frequencies and the acoustic properties of metals is not readily available. Therefore, we investigate the A-scan and C-scan ultrasonic testing data of aluminum alloy, hot rolled steel, stainless steel, and copper alloy, which are used in aircraft bodies, frameworks, and gas pipelines. Experiments are performed with the pulse-width and excitation laser power fixed at $32 \mathrm{~ns}$ and approximately $4 \mathrm{~W}$, respectively. The metal specimens include 24 artificial cylindrical defects with a diameter of $5 \mathrm{~mm}$, located at depths of 1-12 $\mathrm{mm}$ on the front surface. The A-scan and C-scan data obtained at room temperature indicate the detectable depth for metals via the pulse-echo laser ultrasonic propagation imaging technique.
\end{abstract}

Keywords: laser ultrasonics; laser FF PE UPI; non-contact ultrasonic testing; copper alloy; hot rolled steel; stainless steel; aluminum alloy

\section{Introduction}

Composite materials, such as glass fiber reinforced plastics (GFRPs), carbon fiber reinforced plastics (CFRPs), and honeycomb composite sandwich structures, are extensively used in aerospace and other industries. Thus, suitable ultrasonic testing techniques have been investigated for detecting the defects in composite materials [1-3]. If delamination or other defects are present in GFRP, CFRP, or honeycomb composite sandwich structures, the strength of the material can be critically degraded. Therefore, inspection is crucial for composite materials and aluminum alloys, for which ultrasonic testing is an effective method. When an ultrasonic wave impinges on the interface of a medium, it is immediately reflected. The greater the difference in the speed of sound between the media across the interface, the greater the reflection. Compared to solid bodies, gases and vacuum have significantly smaller sound speeds. Since delaminated spaces can be regarded as air or vacuum, the intensity of the reflected ultrasound wave is strong, and the delaminated area can be detected.

To improve the precision and convenience of ultrasonic testing, various techniques have been proposed for ultrasound generation and detection, including laser ultrasonics [4-6]. In laser ultrasonics, high accuracy can easily be achieved owing to the small spot size of the laser beam [7]. Moreover, it is more convenient compared to conventional ultrasonic testing methods, in which couplants such as gel and water are used, because it enables non-contact inspection in air. Ultrasonic laser generation can be categorized into two regimes: ablation and thermoelastic [8,9]. In the ablation regime, the repulsive force of the evaporated particles through the absorption of a high-power pulse laser beam contributes to 
ultrasound generation. Generally, the intensity of the generated ultrasound increases with the pulse laser power; however, there may be exceptions [9]. In the thermoelastic regime, thermoelastic expansion through the absorption of a pulse laser beam generates ultrasound without evaporation. In this regime, the intensity of the generated ultrasound is weaker than that in the ablation regime [8]. One of the methods for detecting ultrasound involves the usage of a continuous laser and an interferometer [10,11]. When the reflected continuous laser beam from the surface of the target arrives at the interferometer, the brightness of the interferometer changes with the surface vibrations; thus, the ultrasound reaching the surface can be detected and analyzed using the interferometer signals.

In this study, we use a laser full-field pulse-echo ultrasonic propagation imaging (FF PE UPI) system [12] for defect detection. In a laser FF PE UPI, ultrasound is generated by an Nd:YAG pulse laser in the thermoelastic regime, the echo-wave is detected by a laser Doppler vibrometer (LDV), and the LDV signals are processed and visualized on a computer as C-scan images, which depict the defect distribution in the target. Using the laser FF PE UPI technique, the successful nondestructive tests of CFRP, GFRP, and 6061-T6 aluminum as well as graphite-to-aluminum, graphite-to-graphite, and steel-to-graphite substrate composite specimens have been reported [12-14].

Although the laser FF PE UPI technique has already been used in aerospace industries, its effectiveness in applications, such as the inspection of steel structures, pipelines, and vessels, is unclear, and further investigation for other materials is required. This study examines the results of the laser FF PE UPI inspection of copper alloy, hot rolled steel, stainless steel, and aluminum alloy specimens. Hot rolled steel is used in steel structures and vessels, whereas copper alloy and stainless steel are mainly used in pipelines. The acoustic properties of steel and copper differ from those of composite materials and aluminum alloy, which are used in aerospace industries. In this study, all the metals are cut into plates, and artificial defects are created on the back of the plates. The results are visualized as A-scan graphs and C-scan images. An A-can graph shows the LDV signals of a single point as time domain, and a C-scan image shows the distributions of the LDV signals on the cross section of a specimen [2,12]. Based on this information, the effectiveness of the laser FF PE UPI technique for metals is assessed.

\section{Experimental}

\subsection{Laser FF PE UPI System}

The laser FF PE UPI system (XNDT Mobile Pulse-Echo UPI System) includes an Nd:YAG laser, LDV, and other components. The LDV uses a 633-nm continuous wave (CW) laser beam with a laser-cavity length of $204 \mathrm{~mm}$ to detect vibration. The area step size of the laser FF PE UPI system is typically equal to the area line spacing. The sampling rate of the LDV signal is fixed for each ultrasound frequency band; for example, the sampling rates of the $50-250 \mathrm{kHz}$ and other bands were $20 \mathrm{MHz}$ and $60 \mathrm{MHz}$, respectively.

Figure 1 shows the A-scan process using the laser FF PE UPI system. When a 1064-nm pulse laser beam is incident on the surface of the specimen, ultrasound is generated and dispersed from the surface to the inner space of the specimen, as shown in Figure 1a. If the ultrasound wave traveling perpendicularly to the surface collides with a defect or the medium interface, it is reflected and returns to the spot shown in Figure 1b. Within several microseconds, the LDV collects the reflected 633-nm CW laser beam as vibration signals on the same point, and a band splitter extracts the specific frequency band from the LDV vibration signals. The A-scan data represent a time-domain graph.

Figure 2 displays the C-scan process using the laser FF PE UPI system. A temperature sensor was attached to a test sample to monitor its temperature and was covered with cork for thermal insulation. After arranging the test samples, two-dimensional scanning, as shown in Figure 1, was performed spot-by-spot. The two-dimensional scan collects the A-scan data of the spot on the scan area and converts them to C-scan images, as shown in Figure 2. 
(a)

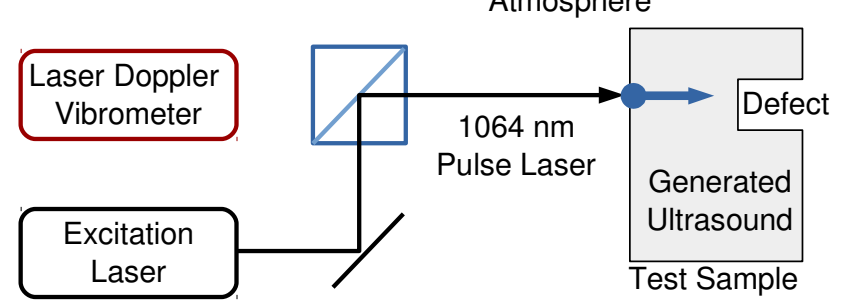

(b)

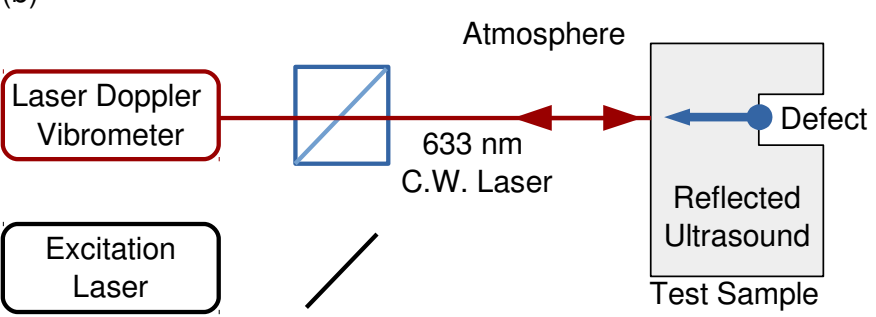

Figure 1. Ultrasound generation and detection with the laser FF PE UPI system: (a) ultrasound generation using a pulse laser beam and (b) detection of the vibrations by a continuous laser beam.

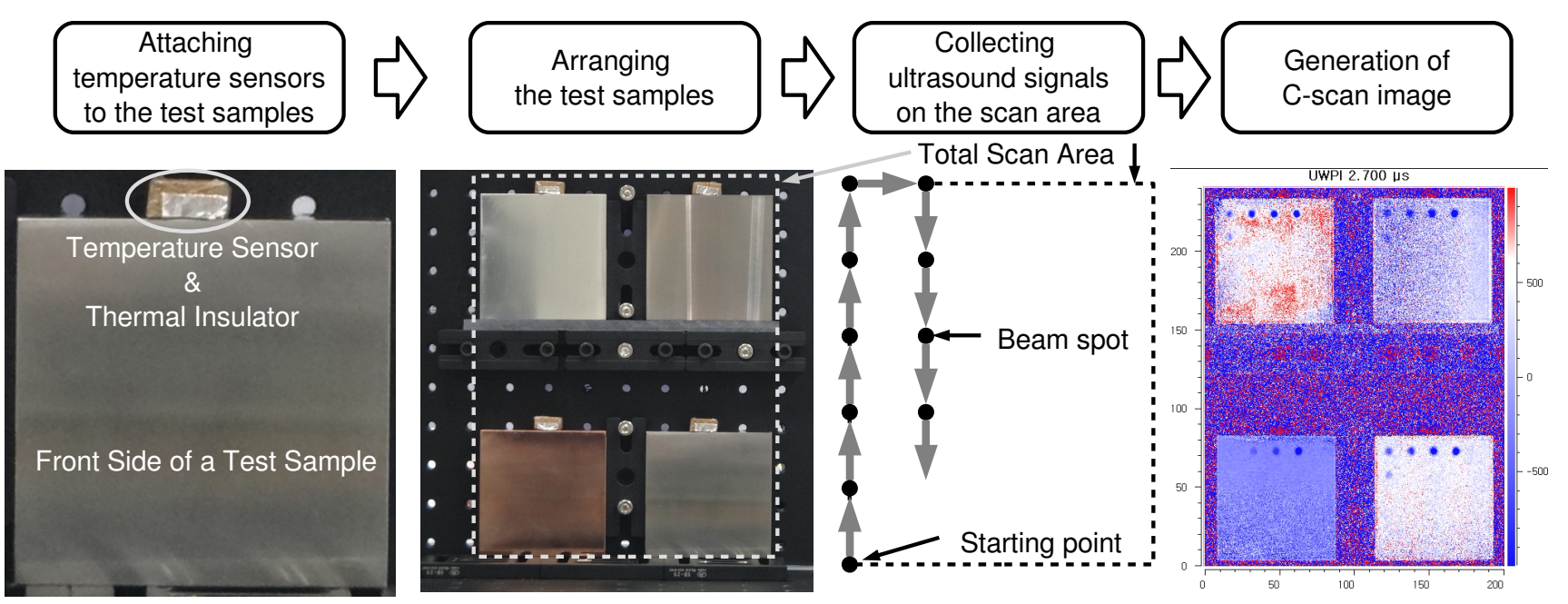

Figure 2. Scanning and generating C-scan images with the laser FF PE UPI system.

The pulse laser beam of the laser FF PE UPI system can drive various ultrasound frequencies, and the LDV can divide the ultrasonic waves into several ultrasound bands. In this study, eight narrow bands were used. The 50-250, 250-500, 500-750, 750-1000, 1000-1160, 1160-1320, 1320 - 1500, and 1500-2500 kHz bands were called Band1, Band2, Band $3, \cdots$, and Band8, respectively, as shown in Figure 3.

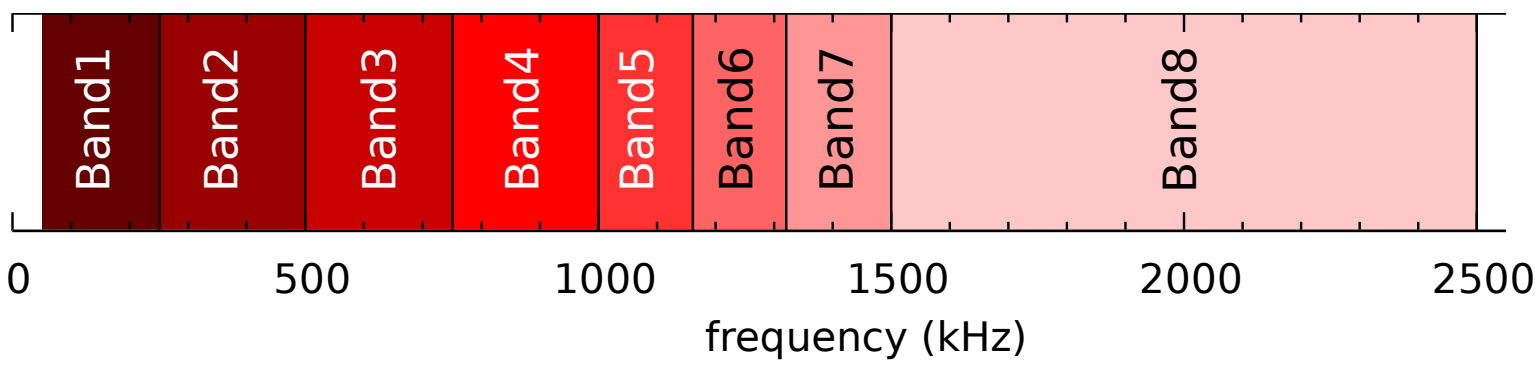

Figure 3. Illustration of the selected ultrasonic narrow bands and the nomenclature.

\subsection{Metal Plate Specimens}

To investigate the effect of the density and ultrasonic speed of the medium on the LDV signal, copper, hot rolled steel, stainless steel, and aluminum specimens were employed. The copper alloy used was phosphor deoxidized copper C1220. In phosphor deoxidized copper, phosphor is added to copper to improve corrosion resistance. C1220 copper is used in gas lines, heater lines, steam and water lines, and tanks. Based on the Korean Industrial Standards (KS), the percentage composition of $\mathrm{Cu}$ must be more than $99.90 \mathrm{wt} \%$ and that of $\mathrm{P}$ must be within the range of $0.015-0.040 \mathrm{wt} \%$ [15]. Hence, $\mathrm{C} 1220$ is equivalent to $\mathrm{C} 12200$. Based on C12200, the density and Young's modulus are $8.94 \mathrm{~g} \cdot \mathrm{cm}^{-3}$ and $117 \mathrm{GPa}$, respectively, [16]. As per pure-copper data, the longitudinal velocity of sound is 
$4.66 \mathrm{~mm} \cdot \mu \mathrm{s}^{-1}$ [17]. The hot rolled steel used was SS400 steel, which is extensively used in the construction and automotive industries. Since the tensile strength must be within the range of 400-510 $\mathrm{MPa}$, the properties and usage of SS400 are similar to those in ASTM A 36. Based on the Japanese Industrial Standards (JIS), the quantity of P and S in the SS400 steel must be less than $0.0050 \mathrm{wt} \%$ [18]. The density, Young's modulus, and longitudinal sound velocity are $7.870 \mathrm{~g} \cdot \mathrm{cm}^{-3}, 214 \mathrm{GPa}$, and $5.920 \mathrm{~mm} \cdot \mu \mathrm{s}^{-1}$, respectively [19]. The stainless steel used was STS304 steel, which is used in chemical and food processing equipment and cryogenic vessels. The Fe quantity must be more than $66.4 \mathrm{wt} \%$, and C, $\mathrm{Cr}$, $\mathrm{Ni}$, and Mn must be $0.08,19.0,9.25$, and $2.0 \mathrm{wt} \%$, respectively [20]. The density, Young's modulus, and longitudinal velocity of sound are $8.00 \mathrm{~g} \cdot \mathrm{cm}^{-3}, 193 \mathrm{GPa}$, and $5.800 \mathrm{~mm} \cdot \mu \mathrm{s}^{-1}$, respectively [21]. The aluminum alloy is the AL6061 aluminum, which is a structural material for aircraft. In the AL6061 alloy, Al must be more than $95.85 \mathrm{wt} \%$, and $\mathrm{Mg}, \mathrm{Si}$, $\mathrm{Cu}$, and $\mathrm{Cr}$ must be 1.0, 0.6, 0.30, and $0.20 \mathrm{wt} \%$, respectively [20]. The density, Young's modulus, and longitudinal sound velocity are $2.80 \mathrm{~g} \cdot \mathrm{cm}^{-3}, 69 \mathrm{GPa}$, and $6.300 \mathrm{~mm} \cdot \mu \mathrm{s}^{-1}$, respectively $[12,20]$.

Figure 4 shows the design of the specimens and the nomenclature. To compare the specimen measurements, all the samples were cut and milled with uniform shapes. The height, width, and depth of the metal plates were 80,80, and $13 \mathrm{~mm}$, respectively. To simulate the defects, holes with a diameter of $5 \mathrm{~mm}$ were drilled on the back of the metal plates, and the vertical and horizontal spacings between the center points were 15 $\mathrm{mm}$. The hole depth varied from 1 to $12 \mathrm{~mm}$. Since the plate's thickness was $13 \mathrm{~mm}$, the thickness of the wall, which is the depth of the artificial defect, varied from 12 to $1 \mathrm{~mm}$. This is referred to as the defect depth.

(a)

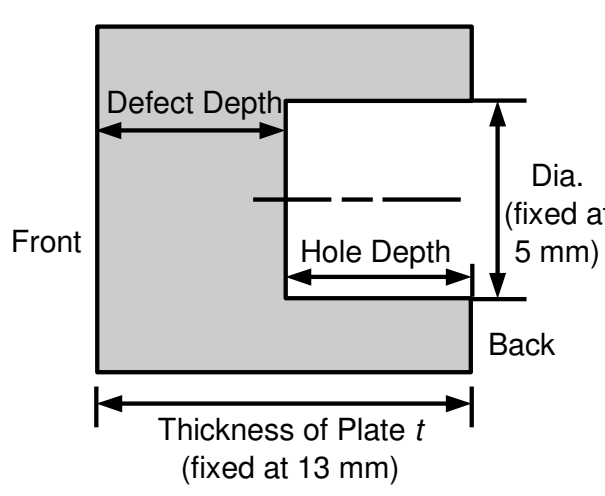

(b)

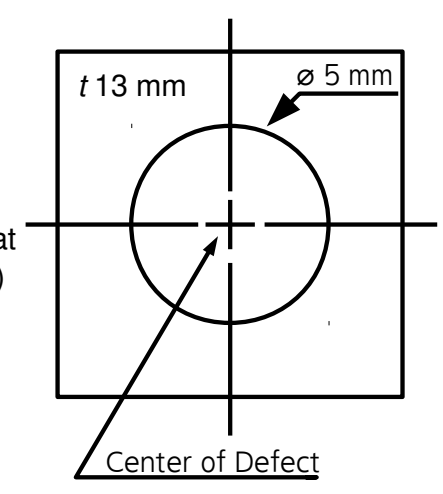

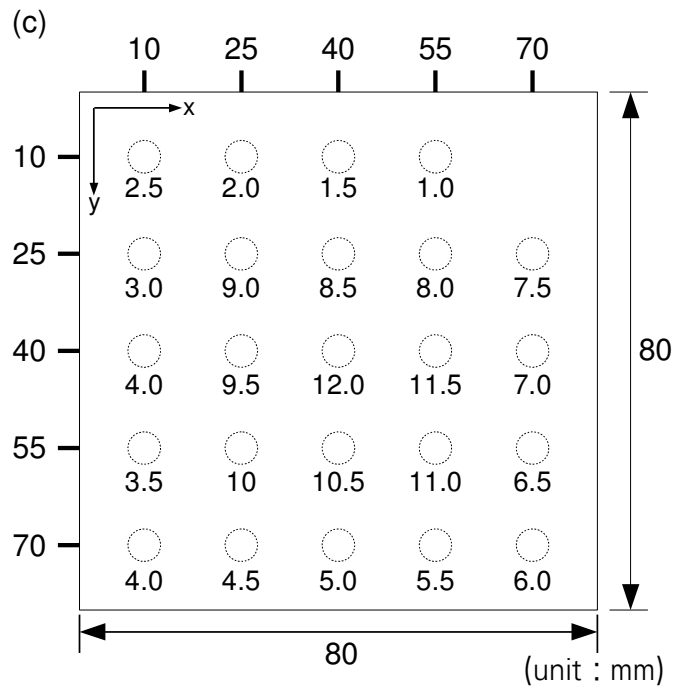

Figure 4. Design and distribution of artificial defects and nomenclature of the parts. (a) Cross-section of a defect, (b) structure of the backside, and (c) front side of a specimen and defect distribution.

Table 1 lists the measured data of the defect depth, shown in Figure 4, for each metal plate using a digital micrometer (Nikon Digimicro MF-501). The observed values are the average of five points on each hole. Defect depths greater than $4.5 \mathrm{~mm}$ were omitted because they were not detected in this study. Artificial defects with designed defect depths of $1.0,1.5,2.0, \cdots$, and $4.5 \mathrm{~mm}$ were denoted as Defect-1.0, Defect-1.5, Defect-2.0, ... and Defect-4.5, respectively. Two artificial detects were designed with a defect depth of $4.0 \mathrm{~mm}$ to investigate the effect of the defect positions; a defect was located at $(10,40)$ $\mathrm{mm}$ and denoted as Defect-4.0-a and the other was located at $(10,70) \mathrm{mm}$ and denoted as Defect-4.0-b. 
Table 1. Measured values of the defect depth.

\begin{tabular}{|c|c|c|c|c|c|c|c|c|c|c|}
\hline Designed & $\begin{array}{l}\text { Depth } \\
\text { Position }\end{array}$ & $\begin{array}{c}1.0 \\
(55,10)\end{array}$ & $\begin{array}{c}1.5 \\
(40,10)\end{array}$ & $\begin{array}{c}2.0 \\
(25,10)\end{array}$ & $\begin{array}{c}2.5 \\
(10,10)\end{array}$ & $\begin{array}{c}3.0 \\
(10,25)\end{array}$ & $\begin{array}{c}4.0 \\
(10,40)\end{array}$ & $\begin{array}{c}3.5 \\
(10,55)\end{array}$ & $\begin{array}{c}4.0 \\
(10,70)\end{array}$ & $\begin{array}{c}4.5 \\
(25,70)\end{array}$ \\
\hline \multicolumn{2}{|c|}{ Copper alloy } & 0.94 & 1.45 & 1.96 & 2.46 & 2.96 & 3.97 & 3.46 & 3.95 & 4.45 \\
\hline \multicolumn{2}{|c|}{ Stainless steel } & 1.04 & 1.54 & 2.03 & 2.52 & 3.01 & 4.00 & 3.49 & 3.99 & 4.48 \\
\hline \multicolumn{2}{|c|}{ Hot rolled steel } & 0.97 & 1.47 & 1.98 & 2.49 & 2.98 & 3.99 & 3.50 & 4.03 & 4.50 \\
\hline \multicolumn{2}{|c|}{ Aluminum alloy } & 0.92 & 1.41 & 1.91 & 2.40 & 2.90 & 3.89 & 3.38 & 3.88 & 4.39 \\
\hline
\end{tabular}

Designed Position ${ }^{+}$denotes the center of the defect position based on Figure 4c. The unit is $\mathrm{mm}$.

\section{Results and Analysis}

The temperature of each metal plate was recorded every second using a digital thermometer (Maxim Integrated DS18B20). During the measurements, the average temperature of the metal plates was $21.2 \pm 0.1{ }^{\circ} \mathrm{C}$. The copper alloy, hot rolled steel, stainless steel, and aluminum alloy plates were measured in a single scan. The height and width of the scan area were 220 and $180 \mathrm{~mm}$, respectively, and the spacing of each beam spot on the metal surface was $0.10 \mathrm{~mm}$. Since the scan step was $0.10 \mathrm{~mm}$, the real size of the C-scan image pixel was 0.10 by $0.10 \mathrm{~mm}$ for each metal plate. The distance from the $633-\mathrm{nm} \mathrm{CW}$ laser head to the metal plate was $846 \mathrm{~mm}$. The pulse repetition rate (PRR) and pulse width of the 1064-nm pulsed laser were $1 \mathrm{kHz}$ and $32 \mathrm{~ns}$, respectively. The power of the pulse laser was approximately $4 \mathrm{~W}$. The data for a single band were collected in a single scan.

\subsection{Characteristics of the Pulse-Echo Laser Ultrasonic Technique}

The LDV signals of the defect surroundings are unequal, and those of the defect areas are inhomogeneous, respectively, as shown in Figure 5. Figure 5a shows the C-scan image of the AL6061 specimen at $6.00 \mu \mathrm{s}$ in Band1, and the point at $(0,0) \mathrm{mm}$ in Figure 5 is the same as that at $(55,10) \mathrm{mm}$ in Figure 4c. In Figure $5 \mathrm{a}$, a gradated ring with an outer radius of approximately $2.5 \mathrm{~mm}$ can be observed. The radius of Defect-1.0 is $2.5 \mathrm{~mm}$, and the minimum value of the color scale bar in Figure $5 \mathrm{a}$ is $-1 \times 10^{4}$. The nonuniformity of the LDV signals at $6.00 \mu$ s is clearly observed in Figure $5 d$, which depicts the LDV signals on the $x$-axis of Figure 5a. In Figure 5d, the LDV signal on the center of Defect-1.0 is the least, and the signal is saturated at the $\pm 2.5 \mathrm{~mm}$ position, beyond which the signal fluctuates.

The difference between the LDV signals of a defect and its surroundings vary over time. Figure $5 b, c$ show the changes in the signals of Figure 5 a over time. When the measuring time is changed from $6.00 \mu \mathrm{s}$ to $7.50 \mu \mathrm{s}$, it is difficult to identify the disc originating from Defect-1.0, as shown in Figure 5b. After $1.5 \mu$ s later from the measuring time shown in Figure $5 \mathrm{~b}$, Defect-1.0 is detected again, as shown in Figure 5c. Figure $5 \mathrm{~d}-\mathrm{f}$ show this tendency clearly. The LDV signals of the surroundings are approximately $-3.9 \times 10^{3}$, and those of the Defect-1.0 area are lower as depicted in Figure 5d. Then, $1.5 \mu$ s later, the LDV signals of the Defect-1.0 area are approximately $-1.5 \times 10^{3}$, and those of the surroundings are approximately $-6.3 \times 10^{2}$, as shown in Figure 5e. In Figure $5 f$, the LDV signals of the surroundings are approximately $1.7 \times 10^{3}$, and those of the Defect-1.0 area are higher.

Figure 6 displays an extreme case of the LDV signal nonuniformity in the same defect area and the disappearance of the detected defects. Figure 6a is the C-scan image of Defect1.0 of the AL6061 specimen at $2.60 \mu \mathrm{s}$ in Band4, and Figure 6b depicts the LDV signals along the $x$-axis of Figure 6a. Figure 6a indicates that a single color and its gradation cannot represent the defect areas, and more than two peaks are observed in Figure 6b. Figure $6 \mathrm{c}$ is the C-scan image of the AL6061 specimen at $3.35 \mu \mathrm{s}$ in Band4. Defects-1.0, 1.5, and 3.0 (bluedisk) and Defects-4.5, 4.0-a, and 4.0-b (red-disk) can be observed. However, Defects-2.0, 2.5, and 3.5 cannot be identified in Figure 6c. Thus, all the detected artificial defects cannot be observed in a single C-scan image (frame). It should be noted that defects can be identified based on the signal difference between the defect area and the surroundings, and the LDV signals of the defects and their surroundings vary constantly during ultrasonic testing with a pulse-echo laser ultrasonic propagation imaging system. 
(a)

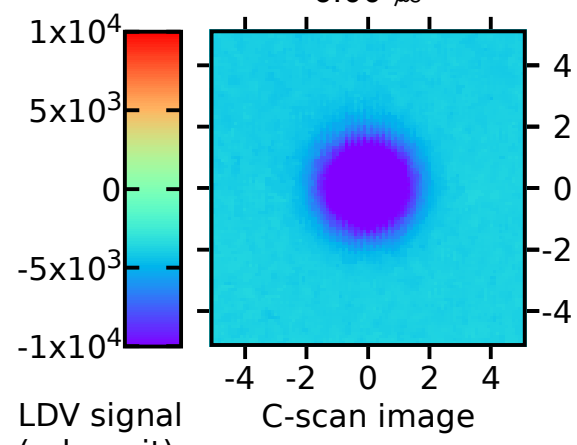

(arb. unit)

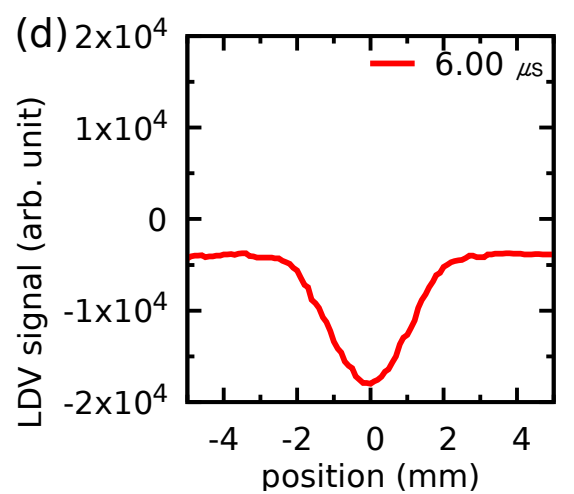

(b)

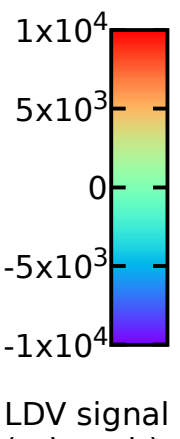

(arb. unit)
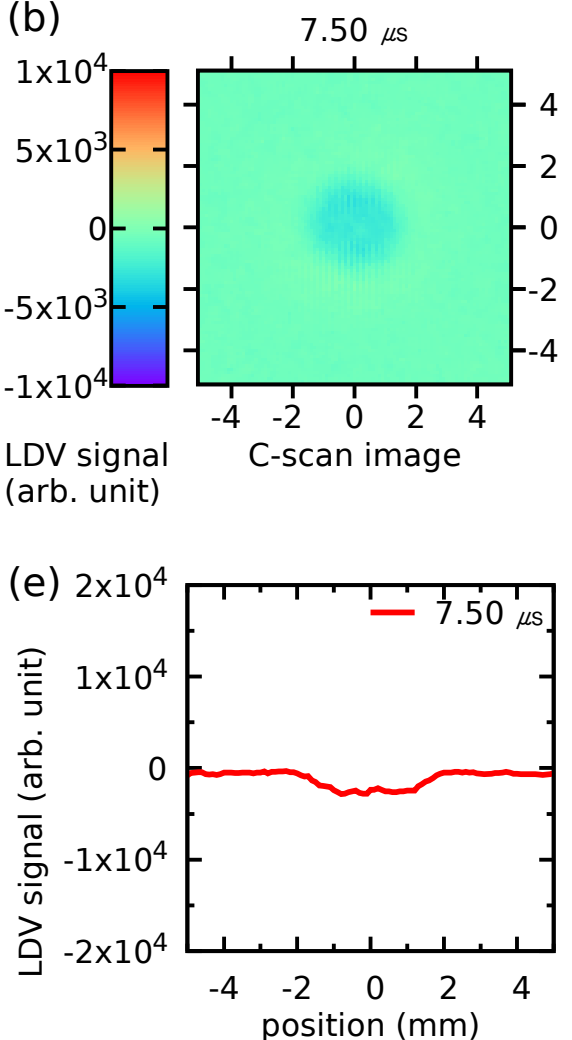

(c)

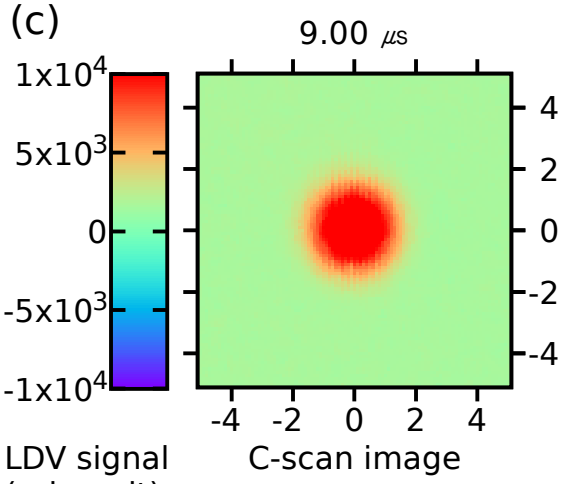

(arb. unit)

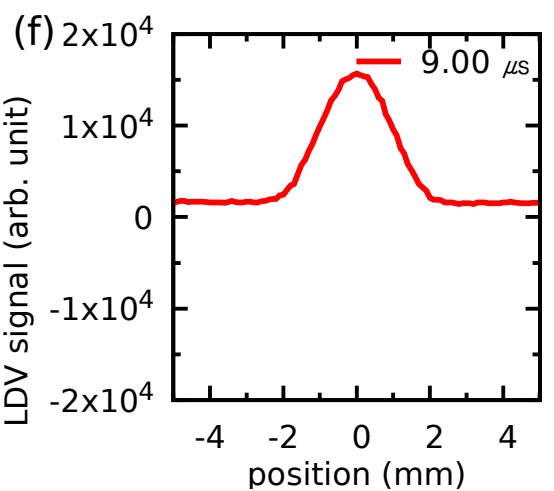

Figure 5. LDV signal distribution for Defect-1.0 of the AL6061 specimen in Band1 and its variation over time: (a-c) C-scan images at 6.00, 7.50, and $9.00 \mu \mathrm{s}$, respectively, and (d-f) LDV signals as a function of the $x$-position at the same measuring time as in $(\mathbf{a}-\mathbf{c})$, respectively. The zero positions in $(\mathbf{d}-\mathbf{f})$ are the same as the origins in $(\mathbf{a}-\mathbf{c})$.

(a)

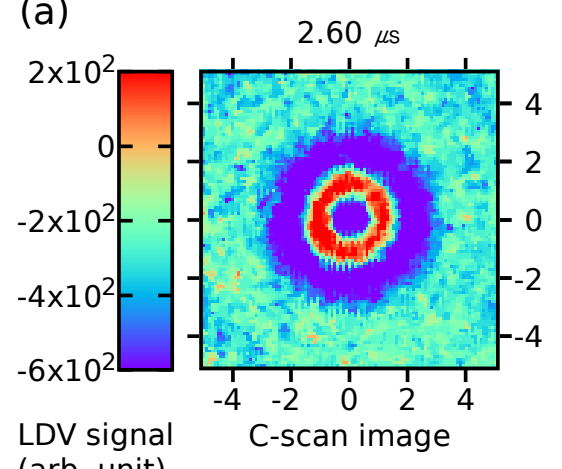

(b)

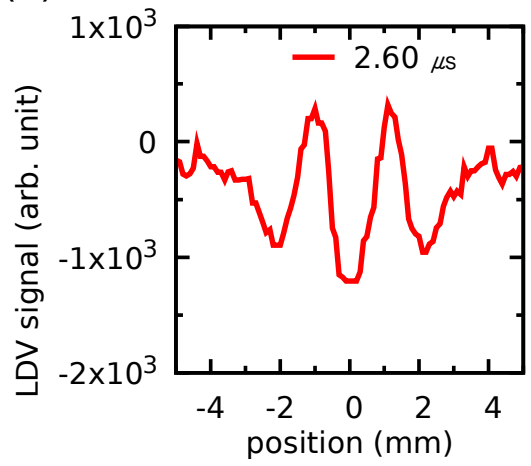

(c)

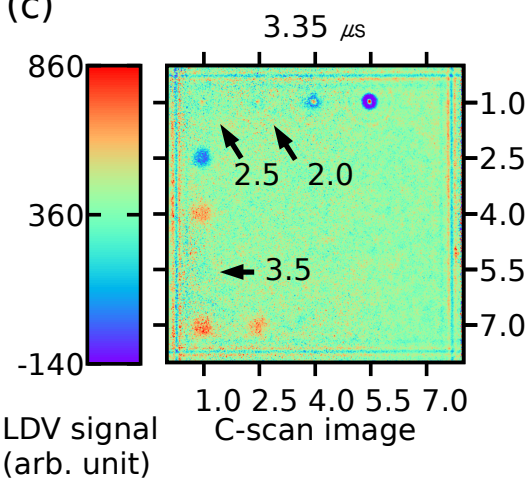

Figure 6. LDV signals of the AL6061 specimen in Band4: (a,b) LDV signals of Defect-1.0 of the AL6061 specimen at 2.60 $\mu \mathrm{s}$, and (c) disappearance of artificial defects such as Defect-2.0, -2.5, and -3.5 of the AL6061 specimen in Band4 when the measuring time is $3.35 \mu \mathrm{s}$.

\subsection{Criterion for the Detected Defects}

Before deriving the maximum detected defect depth, the criterion for the detected defects needs to be discussed. In this study, the mean value of a defect was calculated using a disk that was (orange disk in Figure 7a) concentric with the defect and had a radius of $2 \mathrm{~mm}$. The mean value of the defect surroundings was calculated using a ring that was concentric with the defect and had a radius of $5 \mathrm{~mm}$ (black solid ring in Figure 7a). The measured value was defined as the mean value \pm standard deviation. The standard deviation was also used for the error bars. The number of selected pixels for the mean values of a defect and its surroundings were 1313 and 284, respectively. 
In this study, for a detected defect, the measured values of the defect and its surroundings do not overlap. Simultaneously, the isolated area, originating from the defect, is observed in the $\mathrm{C}$-scan image. For example, Figure $7 \mathrm{~b}$ shows the variation of the LDV signals of Defect-1.0 in Band1; the C-scan images corresponding to 6.00 and $7.50 \mu \mathrm{s}$ in Figure $7 \mathrm{~b}$ are shown in Figure $5 \mathrm{a}, \mathrm{b}$, respectively. At $6.00 \mu$ s in Figure $7 \mathrm{~b}$, the measured values of Defect-1.0 and its surrounding are $-10,006 \pm 3581$ and $-3939 \pm 132$, respectively. Moreover, their error bars do not overlap. In the $\mathrm{C}$-scan image at a measuring time of 6.00 $\mu \mathrm{s}$, Defect-1.0 can be clearly distinguished from its surrounding as shown in Figure 5a. However, at $7.50 \mu \mathrm{s}$ in Figure $7 \mathrm{~b}$, the measured values of Defect-1.0 and its surrounding $(-1514 \pm 844$ and $-638 \pm 90$, respectively) overlap. In the C-scan image at $7.50 \mu \mathrm{s}$, Defect-1.0 cannot be distinguished from its surrounding as shown in Figure $5 \mathrm{~b}$.

(a)

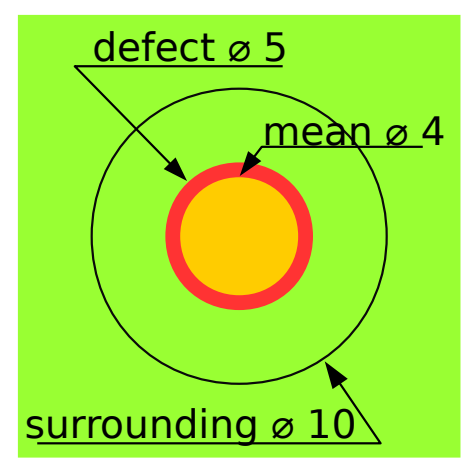

(b)

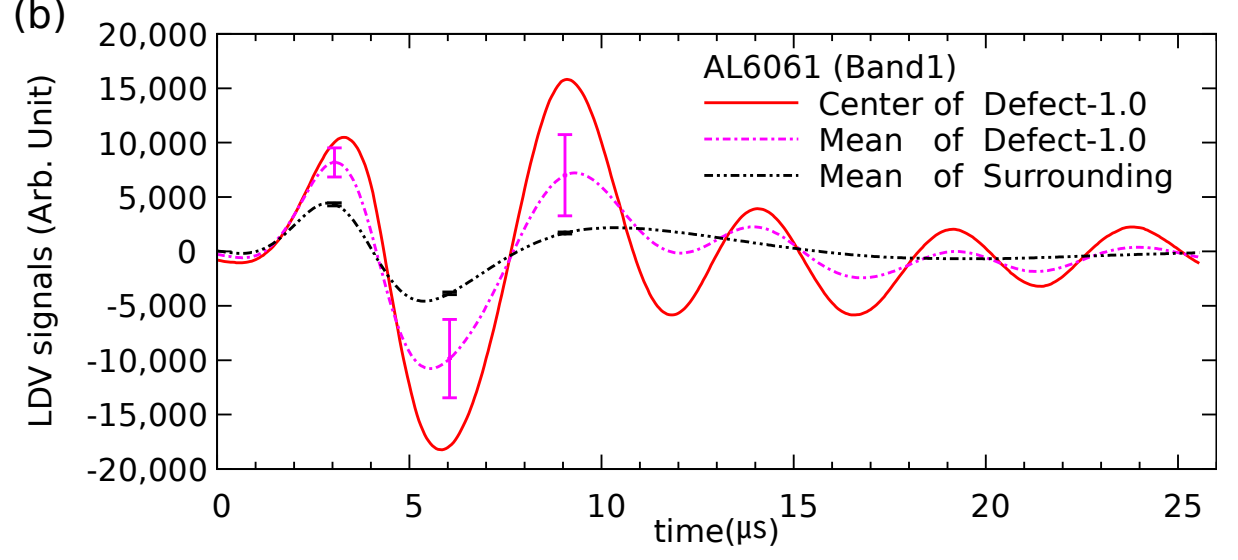

Figure 7. Schematic of the collected pixels for an artificial defect and its surrounding, and A-scan graph of Defect-1.0 and its surrounding in Band1: (a) Description of the range of a defect and its surrounding for the measured values, and (b) LDV signals of Defect-1.0 in the AL6061 specimen as a function of the measured time in Band1.

\subsection{Detected Artificial Defects}

Table 2 presents the detected defects in each band. In the case of the copper alloy C1220 specimen, the deepest detected artificial defect is Defect-3.0 in Band1. Moreover, an increase in the band frequency leads to a decrease in the depth of the detected defect; Defect-1.0 alone can be detected in Band8. In the case of the stainless-steel STS304 specimen, the deepest detected defect is Defect-4.0-a, and the number of the detected defects is the least in Band8. In the case of the hot rolled steel SS400 specimen, the deepest detected defect is Defect-2.0. In the aluminum alloy AL6061 specimen, the deepest detected defect is Defect-4.5 in Band3 and Band4, and, the number of detected defects is the least when Band8 is applied. There is no artificial defect deeper than Defect-4.5, and the number of the detected defects is the least when Band8 is used in all the trials.

All the defects listed in Table 2 cannot be visualized as disks in the corresponding C-scan image. Although Defect-4.0-a in the stainless-steel STS304 specimen is detected at $7.20 \mu \mathrm{s}$ in Band1, its shape is not depicted as a disk in the C-scan image at $7.20 \mu \mathrm{s}$, as shown in Figure 8a. With the increase in the defect depth, the attenuation and dispersion of the reflected wave increase; hence, the LDV-signal difference due to the defect decreases, and the shape of the defect on the C-scan image can be distorted. Defects that are not mentioned in Table 2 are often identified in the C-scan images. Defect- 4.0 -a of the aluminum alloy AL6061 specimen is not detected at $3.10 \mu \mathrm{s}$ in Band5 because the measured values of Defect-4.0-a and its surrounding overlap, as shown in Table 2. However, in the C-scan image at $3.10 \mu \mathrm{s}$, a red spot originating from Defect-4.0-a can be distinguished, as shown in Figure 8b. 
Table 2. Detected artificial defects.

\begin{tabular}{|c|c|c|c|c|c|c|c|c|c|c|}
\hline & & 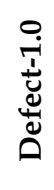 & 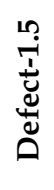 & 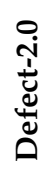 & 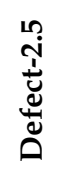 & 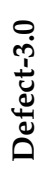 & 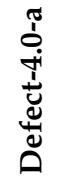 & 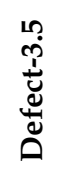 & 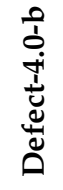 & 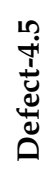 \\
\hline $\begin{array}{l}\text { Copper alloy } \\
\text { (C1220) }\end{array}$ & $\begin{array}{l}\text { Band1 } \\
\text { Band2 } \\
\text { Band3 } \\
\text { Band4 } \\
\text { Band5 } \\
\text { Band6 } \\
\text { Band7 } \\
\text { Band8 }\end{array}$ & $\bigcirc$ & $\begin{array}{l}\bigcirc \\
\bigcirc \\
\bigcirc \\
\bigcirc\end{array}$ & $\begin{array}{l}\bigcirc \\
\bigcirc \\
\bigcirc \\
\bigcirc \\
\bigcirc \\
\bigcirc \\
\bigcirc\end{array}$ & $\bigcirc$ & 0 & & & & \\
\hline $\begin{array}{l}\text { Stainless steel } \\
\quad(\text { STS304) }\end{array}$ & $\begin{array}{l}\text { Band1 } \\
\text { Band2 } \\
\text { Band3 } \\
\text { Band4 } \\
\text { Band5 } \\
\text { Band6 } \\
\text { Band7 } \\
\text { Band8 }\end{array}$ & & $\begin{array}{l}0 \\
0 \\
0\end{array}$ & $\begin{array}{l}0 \\
0 \\
0 \\
0\end{array}$ & & $\begin{array}{l}0 \\
0 \\
0 \\
0 \\
0 \\
0 \\
0\end{array}$ & & & & \\
\hline $\begin{array}{l}\text { Hot rolled steel } \\
\qquad(\mathrm{SS} 400)\end{array}$ & $\begin{array}{l}\text { Band1 } \\
\text { Band2 } \\
\text { Band3 } \\
\text { Band4 } \\
\text { Band5 } \\
\text { Band6 } \\
\text { Band7 } \\
\text { Band8 }\end{array}$ & & 0 & $\begin{array}{l}\bigcirc \\
\bigcirc \\
\bigcirc \\
\bigcirc \\
\bigcirc \\
\bigcirc\end{array}$ & & & & & & \\
\hline $\begin{array}{l}\text { Aluminum alloy } \\
\text { (AL6061) }\end{array}$ & $\begin{array}{l}\text { Band1 } \\
\text { Band2 } \\
\text { Band3 } \\
\text { Band4 } \\
\text { Band5 } \\
\text { Band6 } \\
\text { Band7 } \\
\text { Band8 }\end{array}$ & $\Omega$ & 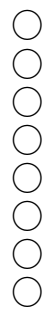 & & $\begin{array}{l}\bigcirc \\
\bigcirc \\
\bigcirc\end{array}$ & $\begin{array}{l}0 \\
\bigcirc \\
\bigcirc\end{array}$ & $\begin{array}{l}0 \\
\bigcirc \\
\bigcirc \\
\bigcirc\end{array}$ & & $\begin{array}{l}0 \\
\bigcirc \\
\bigcirc\end{array}$ & \{ \\
\hline
\end{tabular}

Symbol $\bigcirc$ indicates that the defect is detected in the band.

(a)

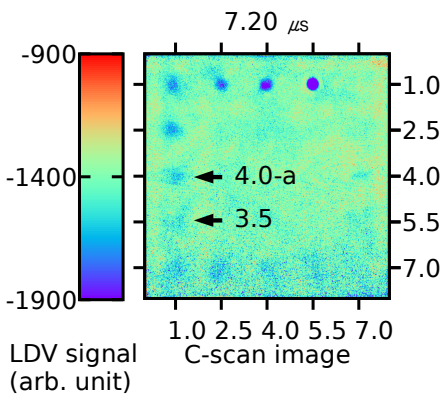

(b)

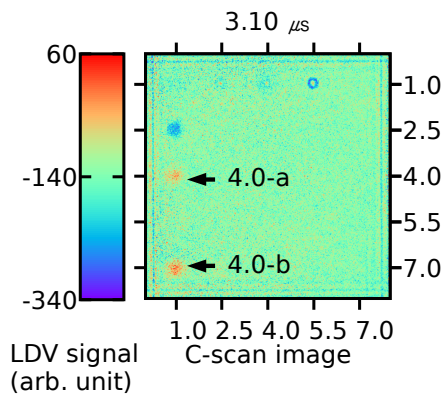

Figure 8. C-scan images of stainless steel STS304 and aluminum alloy AL6061 plates: (a) Stainless steel STS304 plate at 7.20 $\mu$ s in Band1 and (b) aluminum alloy AL6061 plate at $3.10 \mu$ s in Band5.

The A-scan data were affected not only by the defect depth and material, but also by the band. Figure 9a,b show the effect of the defect depth and material, respectively. The arrival time of a longitudinal reflective wave depends on the longitudinal velocity and 
distance, which are determined by the material and the defect depth, respectively. The selected band also affects the A-scan data, as shown in Figure 9c.
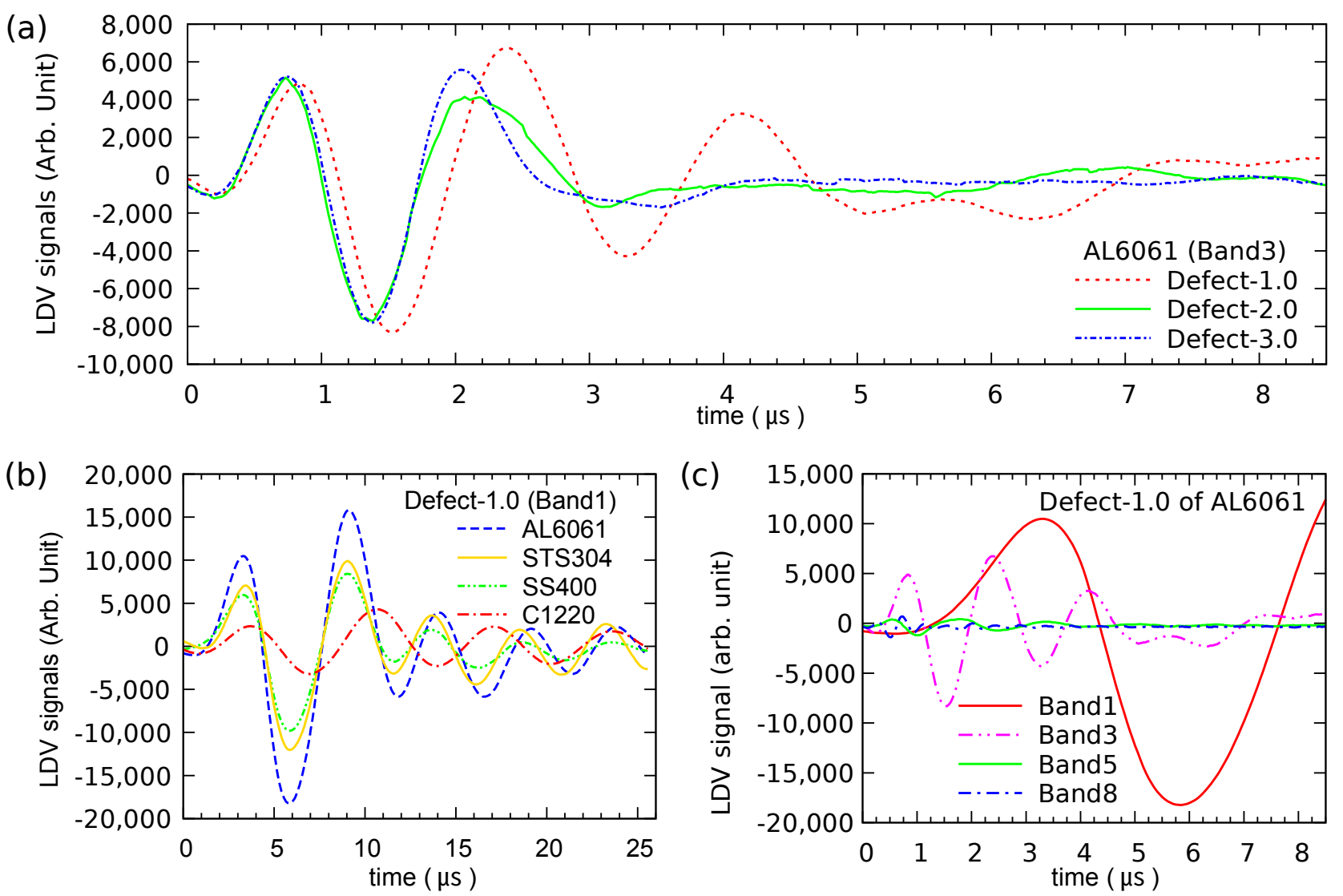

Figure 9. A-scan graphs showing the effect of the defect depth, band, and material: (a) A-scan data of the center of Defects-1.0, -2.0, and -3.0 in aluminum alloy AL6061 in Band3, (b) A-scan data of the center of Defect-1.0 in the AL6061, STS304, SS400, and C1220 specimens in Band1, and (c) A-scan data of the center of Defect-1.0 in aluminum alloy AL6061 in Band1, Band2, Band5, and Band8.

\section{Discussion}

The density and the modulus of the metals were not dominant factors to the maximum detected depth in this study. Usually, the density and the modulus of a metal are major factors of acoustic properties. For example, the shear and the longitudinal velocity can be derived from the Young's modulus, the Poisson's ratio and the density of the metal $[5,7,8,20]$. In Figure 9b, the LDV signals of the STS304 (yellow solid line) and the SS400 (green dotted line) are alike, while their amplitude and phase were quite different from the copper alloy C1220 (red dotted line) and the aluminum alloy AL6061 (blue dash line), until $13 \mu \mathrm{s}$. As mentioned in Section 2.2, the Young's modulus, the Poisson's ratio and the density of the SS400 steel and the STS304 stainless steel are similar to each other. However, the maximum detected depth of the SS400 steel was shallower than C1220 copper alloy, as shown in Table 2. The maximum detected depth was determined by the attenuation of ultrasound, which is affected by absorption and scattering of waves. The microscopic properties, such as grain size and residual strain, are one of the major factors in the absorption and the scattering of ultrasound $[1,6]$.

Averaging data, signal processing, and adjustment of band range can help to detect defects. First, averaging data reduces noise originating from random errors. Second, signal processing can control the effect of anomalous waves. For instance, the laser FF PE UPI system used in this paper can apply the variable time window amplitude mapping (VTWAM) method to scanned data additionally. VTWAM method removes noise originating from the residual incident wave [22]. Last, the suitable ultrasound band range can improve 
the results because the frequency of ultrasound affects diffraction and energy of the wave. To focus on raw data, these methods did not need be applied in this study, but to improve accuracy and detectable depth, these methods have to be considered.

\section{Conclusions}

Non-contact and nondestructive inspections of metal specimens were performed with a pulse-echo laser ultrasonic propagation imaging system using an FF PE UPI technique. In these experiments, the power and pulse-width of the 1064-nm pulsed laser were fixed at $4 \mathrm{~W}$ and $32 \mathrm{~ns}$, respectively. The detectable depth values of the artificial cylindrical defects (5 mm diameter) in C1220 copper, STS304 stainless steel, SS400 hot rolled steel, and AL6061 aluminum specimens were 2.96, 3.49, 1.98, and $4.39 \mathrm{~mm}$, respectively; in addition, defects with a depth of $1 \mathrm{~mm}$ were distinguished in all the specimens and bands. The LDV signals were affected not only by the defect depth and material, but also by the utilized band. Consequently, our results showed that the pulse-echo laser ultrasonic propagation imaging system could detect the defects of C1220, STS304, SS400, and AL6061 metal plates up to a depth of $1 \mathrm{~mm}$, regardless of the used band, when a relatively strong laser of $4 \mathrm{~W}$ is used. The diameter of the defects is larger than $5 \mathrm{~mm}$, and the defects within a depth range of $1-5 \mathrm{~mm}$ could be detected using a suitable band.

Author Contributions: Conceptualization: D.-I.K., K.-R.J. and J.-Y.K.; investigation: D.-I.K.; writingoriginal draft preparation: D.-I.K.; writing-review: Y.-S.J.; project administration: J.-Y.K.; funding acquisition: J.-Y.K. and K.-R.J. All authors have read and agreed to the published version of the manuscript.

Funding: This work was supported by the Korea Institute of Energy Technology Evaluation and Planning (KETEP) and the Ministry of Trade, Industry \& Energy (MOTIE) of the Republic of Korea (No. 70300026), and Korea Institute for Advancement of Technology (KIAT) grant funded by the Korea Government (MOTIE) (P0002092, The Competency Development Program for Industry Specialist).

Institutional Review Board Statement: Not applicable.

Informed Consent Statement: Not applicable.

Data Availability Statement: Not applicable.

Acknowledgments: XNDT maintained the laser FF PE UPI system. Seung-Chan Hong of XNDT provided advice on converting the raw binary data to plot A-scan graphs because the laser FF PE UPI system could only save raw binary data and C-scan images.

Conflicts of Interest: The authors declare no conflict of interest.

\section{References}

1. Jhang, K.Y. Nonlinear ultrasonic techniques for non-destructive assessment of micro damage in material: A Review. Int. J. Precis. Eng. Manuf. 2009. [CrossRef]

2. Kwak, N.S.; Kim, J.Y.; Gao, J.C.; Park, D.K. Reliability Evaluation of Aircraft Brake Disk using the Non-contact Air-coupled Ultrasonic Transducer Method. J. Korean Soc. Manuf. Process Eng. 2016, 15, 36-43. [CrossRef]

3. Lee, J.; Sheen, B.; Cho, Y. Quantitative tomographic visualization for irregular shape defects by guided wave long range inspection. Int. J. Precis. Eng. Manuf. 2015, 16, 1949-1954. [CrossRef]

4. Miao, X.; Li, X.; Hu, H.; Gao, G.; Zhang, S. Effects of the oxide coating thickness on the small flaw sizing using an ultrasonic test technique. Coatings 2018, 8, 69. [CrossRef]

5. Caenen, A.; Pernot, M.; Ekroll, I.K.; Shcherbakova, D.; Mertens, L.; Swillens, A.; Segers, P. Effect of ultrafast imaging on shear wave visualization and characterization: An experimental and computational study in a pediatric ventricular model. Appl. Sci. 2017, 7, 840. [CrossRef]

6. Costa, P.; Nwawe, R.; Soares, H.; Reis, L.; Freitas, M.; Chen, Y.; Montalvão, D. Review of multiaxial testing for very high cycle fatigue: From 'Conventional' to ultrasonic machines. Machines 2020, 8, 25. [CrossRef]

7. Tanaka, T.; Izawa, Y. Nondestructive Detection of Small Internal Defects in Carbon Steel by Laser Ultrasonics. Jpn. J. Appl. Phys. 2001, 40, 1477-1481. [CrossRef]

8. Kim, J.; Jhang, K.Y. Non-contact measurement of elastic modulus by using laser ultrasound. Int. J. Precis. Eng. Manuf. 2015, 16, 905-909. [CrossRef] 
9. Seo, H.; Kim, J.G.; Yoon, S.; Jhang, K.Y. Determination of laser beam intensity to maximize amplitude of ultrasound generated in ablation regime via monitoring plasma-induced air-borne sound. Int. J. Precis. Eng. Manuf. 2015, 16, 2641-2645. [CrossRef]

10. Scruby, C.B.; Dewhurst, R.J.; Hutchins, D.A.; Palmer, S.B. Quantitative studies of thermally generated elastic waves in laserirradiated metals. J. Appl. Phys. 1980, 51, 6210-6216. [CrossRef]

11. Rothberg, S.J.; Allen, M.S.; Castellini, P.; Maio, D.D.; Dirckx, J.J.J.; Ewins, D.J.; Halkon, B.J.; Muyshondt, P.; Paone, N.; Ryan, T.; et al. An international review of laser Doppler vibrometry: Making light work of vibration measurement. Opt. Lasers Eng. 2017, 99, 11-22. [CrossRef]

12. Hong, S.C.; Abetew, A.D.; Lee, J.R.; Ihn, J.B. Three dimensional evaluation of aluminum plates with wall-thinning by full-field pulse-echo laser ultrasound. Opt. Lasers Eng. 2017, 99, 58-65. [CrossRef]

13. Shin, H.J.; Park, J.Y.; Hong, S.C.; Lee, J.R. In situ non-destructive evaluation of an aircraft UHF antenna radome based on pulse-echo ultrasonic propagation imaging. Compos. Struct. 2017, 160, 16-22. [CrossRef]

14. Abetew, A.D.; Hong, S.C.; Lee, J.R.; Baek, S.; Ihn, J.B. Remote defect visualization of standard composite coupons using a mobile pulse-echo ultrasonic propagation imager. Adv. Compos. Mater. 2017, 26, 15-27. [CrossRef]

15. Copper and Copper Alloy Sheets, Plates and Strips. KS D 5201. 2014.

16. C12200 DHP Copper. Available online: http://ameritube.net/PDF/12200.pdf (accessed on 15 October 2019).

17. Accoustic Properties for Metals in Solid Form. Available online: https:/ /www.nde-ed.org/GeneralResources/MaterialProperties/ UT/ut_matlprop_metals.htm (accessed on 15 October 2019).

18. Rolled Steels for General Structure. JIS G 3101. 2004.

19. Murakami, K.; Takemoto, M. Precursor of hydroigen induced glass lining chipping by AE monitoring. J. Acoust. Emiss. 2005, 23, 215-223.

20. Callister William, D.J. Materials Science and Engineering: An Introduction, 6th ed.; WILEY: Hoboken, NJ, USA, 2002.

21. Stella, J.; Cerezo, J.; Rodríguez, E. Characterization of the sensitization degree in the AISI 304 stainless steel using spectral analysis and conventional ultrasonic techniques. NDT E Int. 2009, 42, 267-274. [CrossRef]

22. Lee, J.R.; Chia, C.C.; Park, C.Y.; Jeong, H. Laser ultrasonic anomalous wave propagation imaging method with adjacent wave subtraction: Algorithm. Opt. Laser Technol. 2012, 44. [CrossRef] 